\title{
Class I, II and III major histocompatibility complex gene polymorphisms in BB rats
}

\author{
J. B. Buse, D. D. Chaplin, A. Ben-Nun, K. A. Klein, G. S. Eisenbarth, J. G. Seidman and R. A. Jackson \\ Joslin Diabetes Center, ${ }^{2}$ Brigham and Women's Hospital, ${ }^{3}$ New England Deaconess Hospital and the Departments of \\ ${ }^{4}$ Medicine and ${ }^{5}$ Genetics, Harvard Medical School, Boston, Massachusetts, \\ ${ }^{6}$ Department of Physiology, Duke University Medical Center, Durham, North Carolina, USA
}

\begin{abstract}
Summary. The BB rat spontaneously develops insulin-dependent diabetes mellitus of autoimmune aetiology. From breeding studies, one of the genes necessary for the development of diabetes in these animals is linked to RT1, the rat's major histocompatibility complex. To study further the RT1 linked diabetogenic gene of the $\mathrm{BB}$ rat, we have studied restriction fragment length polymorphism using ${ }^{32} \mathrm{P}$-labelled DNA probes of the major histocompatibility complex genes. As we have previously reported, an I-A $\alpha$ probe (mouse class II gene) defines four chromosome types in the control BBN population, only one of which is found among diabetes prone $\mathrm{BB}$ rats. All $\mathrm{BB}$ rats we have studied are homozygous for the type II a chromosome. Here we examine restriction fragment length polymorphisms using three other DNA probes. Using
\end{abstract}

a DC $\beta$-probe (human class II), the same pattern of polymorphisms (though different molecular weights) is found as with the I-A $\alpha$ probe. An $\mathrm{H}-2^{\mathrm{d}} \mathrm{C} 4$ (fourth component of complement, mouse class III) defines no polymorphisms among or between $\mathrm{BB}$ and $\mathrm{BBN}$ rats. Using $\mathrm{H}-2 \mathrm{~L}^{\mathrm{d}} \mathrm{C}-2$ domain probe (mouse class I) many polymorphisms are apparent and in a limited series distinguishes I-A $\alpha$ defined $\mathrm{II} / \mathrm{II}$ a $\mathrm{BBN}$ rats from $\mathrm{II}$ a/II a BB rats. These studies provide the basis to subtype the RT1 ${ }^{\mathrm{u}}$ identical BB and BBN animals and should aid in the localization and characterization of the RT1 linked diabetogenic gene of the $\mathrm{BB}$ rat.

Key words: Diabetes, major histocompatibility complex, rat, restriction fragment length polymorphism.
Approximately $60 \%$ of $\mathrm{BB}$ rats develop insulin-dependent diabetes. Their disease is similar to Type 1 (insulindependent) diabetes in man and is of autoimmune aetiology [1]. We have confirmed that at least two genes are necessary for the developement of diabetes in crosses of $\mathrm{BB}$ rats with normal rats $[2,3]$. One gene determines the $T$ cell lymphopenia of the $B B$ rat [4] and is autosomal recessive. The second is associated with RT1, the rat major histocompatibility complex. Both genes are necessary but neither alone is sufficient for the development of diabetes in the rat. To examine further the BB rat's RT1 linked diabetogenic gene we have studied restriction fragment length polymorphisms using major histocompatibility complex gene probes on Southern blots in diabetes-prone $\mathrm{BB}$ rats and non-diabetes prone non-lymphopenic BBN rats. We have shown previously, using an I-A $\alpha$ gene probe (mouse class II MHC gene) four distinct chromosome types in the non-diabetes prone, non-lymphopenic BBN population (which reflects the original colony in which diabetes first appeared). In contrast only one of these, called chromosome type IIa, is found among diabetes-prone rats [5]. Here we present initial studies using three other major histocompatibility complex DNA probes (class II $\beta$ chain, complement and class I).

\section{Materials and methods}

Diabetes-prone $\mathrm{BB}$ and non-diabetes-prone $\mathrm{BBN}$ rats were kindly provided by Dr. P. Thibert or bred from his stock in our animal facility. DNA was isolated from rat liver as described previously [6]. Restriction fragment polymorphisms were determined as described by Buse et al. [5]. The I-A $\alpha$ probe was isolated by Dr. A. Ben-Nun and is a $1.3 \mathrm{~kb}$ genomic fragment of the I-A $\alpha$ gene of $\mathrm{C} 57 \mathrm{BL} / 10$ mice [5]. The $\mathrm{DC} \beta$ probe was provided by Dr. P. Peterson and is a cDNA clone of an HLA-DC-like gene [7]. The C4 probe is a genomic fragment which hybridizes with the gene encoding the fourth component of complement in man and mice [probe f, 8]. The $\mathrm{S} 16$ probe is a 500 base pair genomic fragment of the third coding block (C-2 domain) of H-2L [9]. Because of the considerable sequence homology in major histocompatibility complex genes among mammals, it is assumed, though not verified, that these probes hybridize with homologous genes in rats as they do in man and mouse [10]. It should be noted that $\mathrm{BB}$ and $\mathrm{BBN}$ rats are all serologically indistinguishable RT1 ${ }^{\mathrm{u}}$.

\section{Results}

Analysis of restriction fragment length polymorphism involves isolating genomic DNA, digesting with restriction endonucleases which cleave at specific, distinct and relatively rare DNA sequences and separating the resulting DNA fragments by size, using agarose gel electrophoresis. The DNA is then transferred to nitro- 


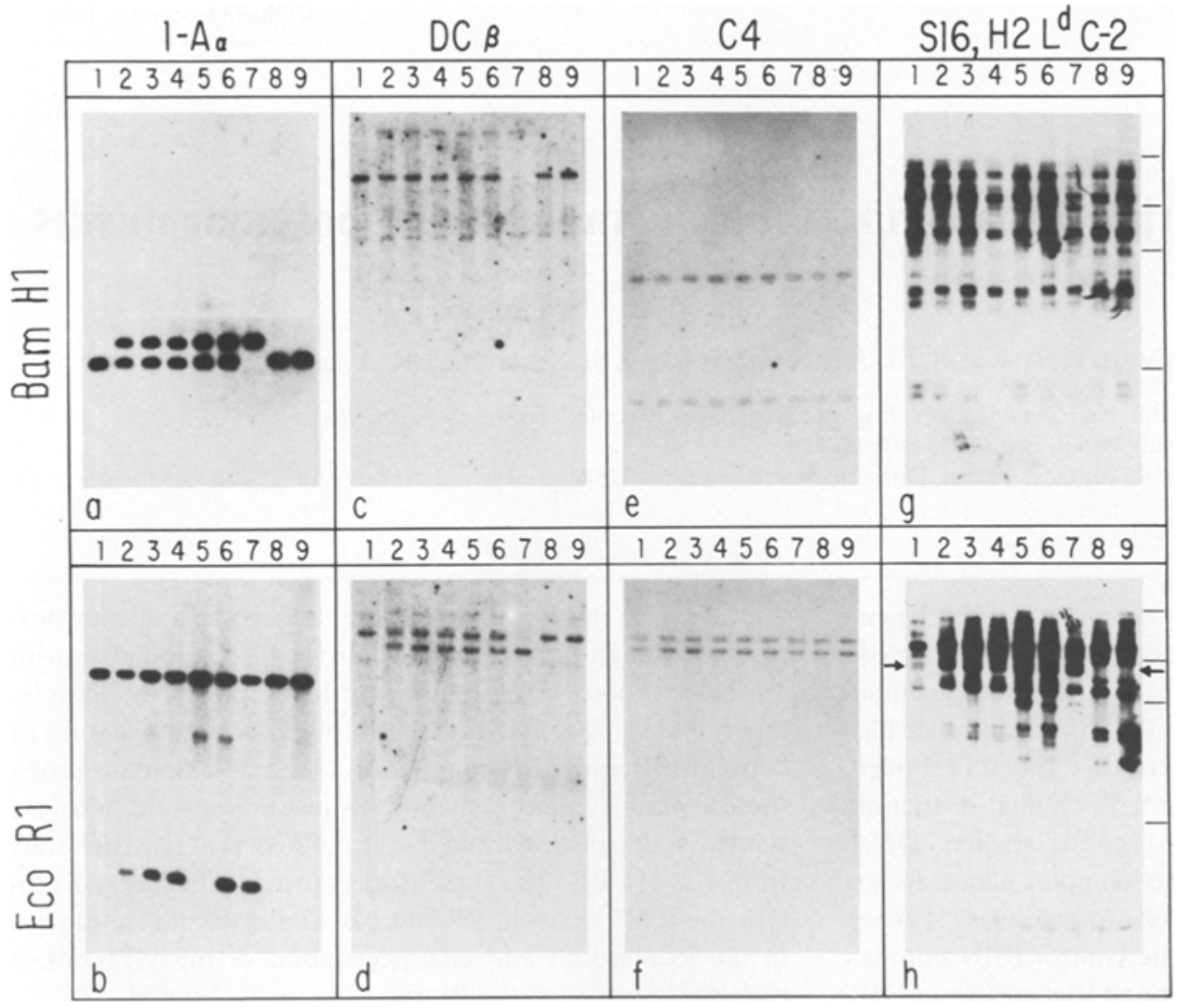

Fig. 1. Restriction fragment length polymorphisms examined in BBN (lanes 1-7) and BB rats (lane 8, diabetic; lane 9 , non-diabetic) using restriction enzymes BamH1 (panels a, c, e,g) and EcoR1 (panels b, d, f, h) with ${ }^{32} \mathrm{P}-1 \mathrm{abell}$ ed I- $\mathrm{A} \alpha$ probe (panels $\mathrm{a}, \mathrm{b}$ ) $\mathrm{DC}-\beta$ probe (panels $\mathrm{c}, \mathrm{d}$ ), $\mathrm{C} 4$ probe (panels e, f), and $\mathrm{S} 16 \mathrm{H}-2 \mathrm{~L}^{\mathrm{d}} \mathrm{C}-2$ domain probe (panels g, h) (see Methods). Each number represents the same rat in all panels. Markers on right axis denote molecular sizes of $23.7 \mathrm{~kb}, 9.5 \mathrm{~kb}, 6.7 \mathrm{~kb}$ and $2.3 \mathrm{~kb}$ from top to bottom. Arrow (panel h) indicates $8.5 \mathrm{~kb}$ EcoR1 band discussed in Results cellulose filters. Such a Southern blot [11] can be examined with ${ }^{32}$ P-labelled DNA probe. Non-specifically bound probe is washed away and bands of hybridized ${ }^{32}$ P-labelled DNA are detected by autoradiography. Polymorphisms are detected as differences in molecular size of DNA fragments which bind labelled probe and are due to DNA sequence variability in the major histocompatibility complex gene probed or in surrounding genetic material.

The result of such an experiment is shown in Figure 1, using restriction enzymes BamH1 (panels a, c, e, g) and EcoR1 (panels b, d, f, h) with the I-A $\alpha$ probe (panels a, b) the DC $\beta$-like probe (panels $\mathrm{c}, \mathrm{d}$ ), the $\mathrm{C} 4$ probe (panel e, f), and the S16, H-2 L $\mathrm{L}^{\mathrm{d}} \mathrm{C}-2$ domain probe (panels $g, h$ ). Each lane contains DNA from an individual rat. Lanes 1-7 represent non-diabetes prone, non-lymphogenic BBN rats. Lanes 8 and 9 contain DNA from a diabetic and a non-diabetic BB rat respectively. Each number represents the same rat in all panels.

Using the I-A $\alpha$ probe (panels a, b), several restriction fragment length polymorphisms are apparent among the non-diabetes-prone BBN rats, while the two $\mathrm{BB}$ rats share the same polymorphism. In a population study, all $\mathrm{BB}$ rats $(n=12)$ and BB-derived strains $(n=10)$ are homozygous for one of the four chromosome types (IIa) present among the BBN population [5]. A minority of $B B N$ rats (16 out of 81 studied) express the same 1-A $\alpha$ defined pattern as the BB rats. However, we would not expect them to develop diabetes because they are not lymphopenic [5].

The DC $\beta$ probe (panels $\mathrm{c}, \mathrm{d}$ ) defines no additional polymorphisms compared with the I-A $\alpha$ probe. Its prominent BamH1 band and upper EcoR1 bands have an identical pattern for reactivity to the lower BamH1 I-A $\alpha$ defined band.

The lower DC $\beta$ EcoR1 band has the same pattern of reactivity as the upper BamH1 I-A $\alpha$ defined band. The I-A region of mouse major histocompatibility complex and the DC region of human major histocompatibility complex are homologous and these two probes probably define very closely linked class II genes encoding the $\alpha$ chain and $\beta$ chain of the RT1. B locus of the rat [10]. These class II genes are highly polymorphic in man and mouse [12].

The C4 probe defines no polymorphisms either among or between BBN and BB rats. Similar results have been found in serologically related mouse strains using major histocompatibility classe III gene probes [8].

The S16, H-2 $\mathrm{L}^{\mathrm{d}} \mathrm{C}-2$ domain probe hybridizes to many bands. In man and mouse $20-40$ class I genes are present, though only a few are expressed [13]. Among the seven BBN rats, at least five different patterns are evident using restriction enzyme EcoR1 and the S16 probe (lanes 1, 2-4, 5, 6 and 7). Additionally, this probe allows us to distinguish the two $\mathrm{BB}$ rats from rat $\mathrm{BBN} / 1$, a non-diabetes prone rat which is identical to 
the $\mathrm{BB}$ using the I-A $\alpha$ and $\mathrm{DC} \beta$ class II gene probes. In particular, a band of approximately 8.5 kilobases is present in the BBN IIa/IIa animal which is absent in the $\mathrm{BB}$ animals.

\section{Discussion}

As we have reported previously in a population study, the I-A $\alpha$ probe in conjunction with restriction enzymes BamH1 and EcoR1 define four polymorphic chromosome types in the non-diabetes-prone BBN rat population. All diabetes-prone $\mathrm{BB}$ rats and $\mathrm{BB}$ derived strains are homozygous for one of these (type IIa/IIa; BamH1 $2.4 \mathrm{~kb}$; EcoR1 $8.2 \mathrm{~kb}$ ) [5] as shown in panels a and b. In a small number of animals, the closely related DC $\beta$-like probe defines similar polymorphisms. The $\mathrm{C} 4$ probe defines no polymorphisms among $\mathrm{BB}$ and $\mathrm{BBN}$ rats. The S16, H-2 L ${ }^{\mathrm{d}}$ C-2 domain, class I probe hybridizes with many bands, consistent with the presence of multiple closely related class I genes. The S16 probe also defines multiple polymorphisms in this small sample, a common finding among serologically class I identical mouse strains [13]. Additionally, the S16 probe allows us to distinguish the two BB rats in this study from the one $\mathrm{BBN}$ rat that is otherwise indistinguishable using the class II probes. None of these probes define polymorphisms between the two BB rats despite their obvious phenotypic differences, the presence or absence of diabetes.

Class II and now class I probes have allowed us to distinguish between serologically indistinguishable $\mathrm{BB}$ and $\mathrm{BBN}$ rats. It is of particular interest that all $\mathrm{BB}$ rats are homozygous for what we have termed the class IIa chromosome even though amongst $\mathrm{BBN}$ animals this chromosome is much less frequent than type $\mathrm{Ia}$ and $\mathrm{Ib}$ chromosomes. Both the $\mathrm{BB}$ and BBN rats are maintained as outbred colonies and thus it is unlikely that this dramatic difference is secondary to chance breeding. In addition, all BB derived strains we have studied (Dr. Logothetopoulos's BB-hooded rats and Dr. A. A. Like's BB/W strain) are homozygous IIa/IIa. We suspect that enrichment for the type IIa chromosome in BB rats has resulted from selection pressure for diabetes and perhaps only this chromosome carries the RT1 linked diabetogenic gene(s). To study extended haplotypes we have used another class II probe, a class III probe and a class I probe. The class I probe gives additional information and should allow us to define further the chromosomes enriched in the BB rat strain. Breeding studies to define accurately the linkage to diabetes of these polymorphisms are underway and should con- tribute to the localisation and eventual characterization of the BB rat's RT1-linked diabetogenic gene.

Acknowledgements. The authors wish to thank V.Abrahamsen and P.Cronin for their help in the preparation of this manuscript; Dr. P. Thibert for providing us with the animals; Dr. P. Peterson for the HLA-DC-like $\beta$ cDNA probe, and Dr. J. Weis for the S16 probe. This work was supported by NIH grants GM 07171, AM 25778, and AI 18436 and American Cancer Society grant JFRA66. R. Jackson is a recipient of a fellowship award and G. Eisenbarth is a recipient of a Career Development Award from the Juvenile Diabetes Association.

\section{References}

1. Buse JB, Rowley RF, Eisenbarth GS (1982) Disordered cellular immunity in Type I diabetes of man and the BB rat. Surv Immunol Res 1:339-351

2. Jackson RA, Buse JB, Rifai R, Pelletier D, Milford EL, Carpenter CB, Eisenbarth GS, Williams RM (1984) Two genes required for diabetes in BB rats: evidence from cyclical intercrosses and backcrosses. J Exp Med (in press)

3. Colle E, Guttman RD, Seemayer TA, Michel F (1983) Spontaneous diabetes mellitus syndrome in the rat. IV. Immunologic interactions of $\mathrm{MHC}$ and non-MHC components of the syndrome. Metabolism 32 (Suppl 1): 54-61

4. Jackson R, Kadison P, Buse J, Rassi N, Jegasothy B, Eisenbarth GS (1983) Lymphocyte abnormalities of the BB rat. Metabolism 32 (Suppl 1): 83-86

5. Buse JB, Ben-Nun A, Klein KA, Eisenbarth GS, Seidman JG, Jackson RA (1984) Specific class II histocompatibility gene polymorphism in BB rats. Diabetes (in press)

6. Blin N, Stafford D (1976) A general method for isolation of high molecular weight DNA from eukaryotes. Nucleic Acids Res 3: 2303-2309

7. Larlimmar D, Schenning L, Gustafsson K, Wiman K, Glaesson L, Rask L, Peterson P (1982) Complete amino acid sequence on an HLA-DR antigen-like chain as predicted from nucleotide sequence. Proc Natl Acad Sci USA 79: 3687-3691

8. Chaplin DD, Woods DE, Whitehead AS, Goldberger G, Colten H, Seidman JG (1983) Molecular map of the murine S region. Proc Natl Acad Sci USA 80: 6947-6951

9. Evans GA, Margulies DH, Camerini-Otero RD, Ozato K, Seidman JG (1982) Structure and expression of a mouse major histocompatibility antigen gene, $\mathrm{H}-2 \mathbf{L}^{\mathrm{d}}$. Proc Natl Acad Sci USA 79: 1994-1998

10. Gill TJ III, Cramer DV, Kunz HW, Misia DN (1983) Structure and function of the major histocompatibility complex of the rat. J Immunogenet 10: 261-273

11. Southern E (1975) Detection of specific sequences among DNA fragments separated by gel electrophoresis. J Mol Biol 98: $503-517$

12. Auffray C, Ben-Nun A, Roux-Dosseto M, Germain RN, Seidman JG, Strominger JC (1983) Polymorphism and complexity of human DC and murine I-A chain genes. Europ Molec Bid Org J $2: 121-124$

13. Steinmetz M, Hood L (1983) Genes of the major histocompatibility complex in mouse and man. Science 222: 727-733

Dr. Richard A.Jackson

Research Division

Joslin Diabetes Center

1 Joslin Place

Boston, MA 02215

USA 